\title{
AGENDA PÓS-MODERNA E NEOPOSITIVISMO: ANTÍPODAS SOLIDÁRIOS
}

\author{
Sandra Soares Della Fonte*
}

RESUMO: Este artigo toma como foco duas questôes norteadoras: qual o lugar que o pós-estruturalismo e o neopragmatismo ocupam na produção do conhecimento referente aos estudos do currículo? Quais os desdobramentos éticos, políticos e filosóficos dessas orientaçôes teóricas para o campo educacional em geral? Ao tratar dessas indagações, o texto coloca em xeque crenças subscritas quanto a essas duas perspectivas teóricas no campo de estudos do currículo, quais sejam: o pós-estruturalismo e o neopragmatismo colaboraram para a oposição à tradição positivista; fortaleceram a noção de convivência democrática pela defesa da pluralidade e da diferença; enriqueceram a produção do conhecimento acadêmico da educação e a criação de práticas inovadoras de viver o currículo.

Palavras-chave: Pesquisa educacional. Currículo. Pós-moderno. Neopositivismo. Ontologia.

\section{POSTMODERN AGENDA AND NEOPOSITIVISM: CONNECTED ANTIPODES}

ABSTRACT: This paper focuses on two questions: what is the place of post-structuralism and neopragmatism in the production of knowledge on curriculum studies? What are their ethical, political and philosophical consequences for the educational field in general? When dealing with these issues, the text brings into question some beliefs about these two theoretical trends, such as: they contribute to oppose the Positivist tradition; they strengthen the notion of democratic coexistence by defending plurality and difference; finally, they

Doutora em Educação e professora adjunta da Universidade Federal do Espírito Santo (ufEs).E-mail:sdellafonte@uol.com.br 
enrich the production of academic knowledge in education and the creation of innovative practices for experiencing the curriculum.

Key words: Education research. Curriculum. Post-modern. Neopositivism. Ontology.

\section{Uma nota preliminar ou o término da conversação}

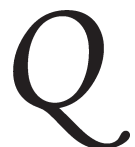

uando trata da pesquisa sobre currículo como um acontecimento, Corazza (2004) defende algumas imagens para qualificar a pesquisa em educação: pesquisa em fuga, pesquisa-filosofia, pesquisa da besteira, pesquisa noológica, pesquisa empirista transcendental, Gaia pesquisa, entre outras. Todas essas imagens comungam a mesma feição. Trata-se, segundo a autora, de uma pesquisa "despojada de qualquer significação" que

(...) não consiste num ato subjetivo decorrente de condições empíricas negativas, como a ignorância do sujeito pesquisante, nem trata de ultrapassar obstáculos contingentes de desconhecimento acerca de algum fenômeno educacional, como se pesquisar fosse uma passagem do não-saber ao saber (...). (Corazza, 2004, p. 2)

Ao abrir mão da vontade de representação, essa forma de pesquisar conduz a “(...) pensar um currículo sem pressupostos (...), [a] transformar todas as opiniōes curriculares nas idiossincrasias de um estilo de pensar-criar o currículo de outros modos" (idem, ibid., p. 4). Conforme Corazza, sob essa ótica, a pesquisa em educação não pretende instaurar uma longa discussão, na qual triunfa o melhor argumento ou da qual deriva a aceitação de um consenso. Além disso, "Há mesmo um lado pragmático da Pesquisa em Fuga que é contra a teoria, na medida em que os pesquisadores só podem realmente pesquisar onde aquilo que deve ser pesquisado não foi já dado (...)" (idem, ibid., p. 11).

De posições semelhantes a essa, defendida por Corazza, decorre o entendimento da produção do conhecimento como uma atividade poética: "Poetizar, nesse caso, significa produzir, fabricar, inventar, criar sentidos inéditos. Novos olhares! Novas conexões! Novas sinapses! Novos sentidos! É isto o que as produções pós-críticas têm mobilizado no campo da educação brasileira" (Paraíso, 2004, p. 295-296). 
No momento em que se apresenta a produção do conhecimento como uma espécie de poética do dizer, os estudos curriculares convertem-se em conversaçôes curriculares. Nesse horizonte, o pós-estruturalismo e o neopragmatismo assumem uma posição de destaque na produção acadêmica da área, pois, a despeito de suas peculiaridades, depuram do pesquisar qualquer pretensão de representar propriedades e qualidades objetivas do real e se encerram em conversaçôes infinitas, cujo interesse se circunscreve a e é impulsionado pela própria poética do conversar.

Conceber os estudos do currículo como conversaçôes curriculares representa uma posiçãa digna de problematização. Afinal, conversação não é um termo qualquer no léxico filosófico. Nos estudos do neopragmático Richard Rorty, o papel conferido à filosofia por ele chamada de edificante (em contraposiçãao à sistemática) é a busca pela conversação. Segundo ele, na conversação, não se diz algo sobre alguma coisa, não se tem a intenção de representar a realidade, realizar um programa de pesquisa ou descobrir a verdade. Os filósofos edificantes contribuem para evitar que a filosofia se deixe levar pelo desejo de seguir "a trilha segura da ciência" (Rorty, 1994, p. 365-366) e para "(...) prevenir que o homem se iluda com a noção de que conhece a si mesmo, ou a qualquer outra coisa, exceto sob descriçōes opcionais" (p. 371).

Nessa perspectiva, a filosofia como conversação entre e com os filósofos é geradora de descrições novas e inéditas. Assim, para Rorty (op. cit., p. 363), "Os grandes filósofos edificantes são reativos e oferecem sátiras, paródias, aforismos. (...) Os filósofos edificantes desejam manter o espaço aberto para o sentido de admiração que os poetas podem causar às vezes (...)". Rorty considera que qualquer desejo de comensuração universal, de dizer o que a realidade é, de hipostasiar uma descrição em detrimento de outras é uma forma de encerrar "a conversação livre e ociosa" (op. cit., p. 381). Afinal, como esse filósofo admite, “(...) o modo como as coisas são ditas é mais importante do que a posse de verdades" (p. 353).

Sob a ótica rortyana, afirmar que o pós-estruturalismo e o neopragmatismo promovem, nos estudos curriculares, conversaçôes implica trazer à baila o conjunto de descriçóes que essas perspectivas teóricas têm gerado e incentivado quanto aos estudos do currículo escolar. Quais narrativas surgiram dessa conversação? Que metáforas inéditas foram criadas e fomentadas? Até que ponto elas estimulam a proliferação 
de novas descrições e a continuidade da conversação? Será que as descrições pós-estruturalistas e neopragmáticas sobre o currículo têm nos causado a admiração semelhante àquela provocada pela poesia? Elas têm se mostrado melhores e mais úteis para a nossa lida cotidiana com as questôes curriculares do que outras descriçōes?

Adianto que, infelizmente, frustrarei aquelas e aqueles que esperam essa abordagem. Não farei esse elogio à autorreferencialidade da linguagem; obviamente, acredito que a linguagem humana mereça ser elogiada infinitas vezes quantas formos capazes de honrá-la. Contudo, não considero que seja esse o papel da filosofia. Transformado em uma exercitação linguística autorreferente, o conhecimento filosófico se submete a devaneios subjetivos e alheamento do mundo exterior, fato que o conduz àquilo que Delacampagne (1997, p. 272) chama de "autismo filosófico".

A conversão da filosofia na busca de modos melhores e mais interessantes de falar (muito característica da "virada linguística") contribui para colocar na ordem do dia um debate clássico na tradição filosófica: a distinção entre o filósofo e o sofista. De maneira mais precisa, ela simboliza, nos dias atuais, a revanche da sofística contra a filosofia.

Não por acaso, proclama-se atualmente a ontologia como um efeito do dizer, o discurso como fabricação do real e a impossibilidade de distinguir o falso do verdadeiro (pois, tão logo o falso é dito, ele é tanto como o verdadeiro). $\mathrm{Ou}$, em um nível mais avançado, apresenta-se a proliferação do discurso a partir de si mesmo como uma espécie de palimpsesto, reivindica-se a ficção, assume-se o estilo oracular, promove-se a descompartimentação dos gêneros discursivos (o que implica não diferenciar o uso filosófico e o literário da língua) e se anuncia a era da hermenêutica. ${ }^{1}$

Diante do forte apelo midiático, das promessas de benesses do mercado, da proclamação do fim dos projetos revolucionários, do decreto de falência da razão, do predomínio de posturas céticas e relativistas, o efeito sofístico não seria o fim perseguido pelo intelectual deste novo tempo? Nesse caso, talvez se deva atentar para o fato de que, sob discursos sobre pluralidade e participação política, se está, na verdade, na presença de uma nova versão daquela figura caracterizada por Platão (1987) como caçador interesseiro de jovens ricos e comerciante em ciências, que transforma a política na arte da eloquência e a produção do conhecimento em treinamento retórico sem compromisso com a verdade. 
Por isso, termino a conversação para iniciar o debate argumentado e ancorado na possibilidade de dizer algo sobre as relações constitutivas do mundo objetivo, mesmo que dentro de limites históricos, sociais e pessoais. Ora, se a conversação findou no momento mesmo de seu início, cabe registrar o que se fará neste artigo. Prolongo o atrevimento inicial de por em xeque a posição das chamadas teorias pós-críticas da educação e destaco duas questões norteadoras deste texto: qual o lugar que o pós-estruturalismo e o neopragmatismo ocupam na produção do conhecimento referente aos estudos do currículo? Quais os desdobramentos éticos, políticos e filosóficos dessas orientações teóricas para o campo educacional em geral?

Com essas questões, pretendo tocar em algumas crenças subscritas quanto a essas duas perspectivas teóricas no campo de estudos do currículo, quais sejam: o pós-estruturalismo e o neopragmatismo colaboraram para a oposição à tradição positivista; fortaleceram a noção de convivência democrática pela defesa da pluralidade e da diferença; enriqueceram a produção do conhecimento acadêmico da educação e a criação de práticas inovadoras de viver o currículo. Em um sentido contrário, coloco sob suspeitas essas assertivas e sugiro:

1) O pós-estruturalismo e o neopragmatismo são construções teóricas com trajetórias históricas próprias e categorias e conceitos peculiares. As diferenças entre ambas são inúmeras (cf. Rorty, 1999). A despeito dessas diferenças, proponho compreendê-las como integrantes de um amplo clima intelectual e político que se corporifica em uma agenda denominada de pós-moderna (Wood, 1999). ${ }^{2}$ O pós-estruturalismo e o neopragmatismo ocupam um lugar especial nesta agenda, pois o estatuto filosófico de seus argumentos permite que eles penetrem e se articulem a discussóes de campos acadêmicos variados e temas diversos.

2) As distintas formas discursivas da agenda pós-moderna delineiam sua discordância da neutralidade advogada pelos positivistas: o conhecimento não é neutro, mas produto dos interesses, valores, crenças de uma comunidade. Apesar de sua luta contra o positivismo, a agenda pós-moderna é portadora de um caráter criptopositivista. 
3) Ainda que afirme sua filiação à tradição política de esquerda, tal agenda se aproxima e/ou fortalece, muitas vezes a contragosto de seus anúncios, posições conservadoras.

4) Por mais que se acumulem textos, artigos, relatos de experiências inspirados por essas duas perspectivas teóricas, o processo que elas têm ratificado representa aquilo que Moraes (2003) denominou de "recuo da teoria" na produção do conhecimento no campo educacional e Loureiro (2007) caracterizou como um duplo processo: de aversão à teoria e indigência da prática educativa.

Considerando as limitaçōes de um artigo, pretendo, a partir das questôes norteadoras anunciadas, levantar indícios dessas provocações.

\section{Os estudos do currículo e a agenda pós-moderna}

Em que consiste o currículo escolar? Como organizá-lo? Que princípios devem nortear a seleção de conteúdos e métodos de ensino? Como justificar a escolha do que é ensinado nas escolas? Qual a relação entre currículo e cultura? O projeto de formação de um sujeito livre, responsável e autônomo ainda se sustenta como ideal educativo orientador da organização curricular?

Essas são algumas indagações que têm mobilizado a pesquisa relativa ao currículo escolar nos dias atuais. No seu cerne, essas questóes nos levam a perceber como parcela significativa do debate contemporâneo na área educacional tangencia, de alguma maneira, o tema da modernidade e da herança iluminista e, não raramente, respostas são dadas em uma perspectiva de educação marcada por aquilo que Moraes (1996) chamou de "pós-ismos".

Como se configuram, em termos de produção de conhecimento, essas respostas? Veiga-Neto e Macedo (2007, p. 11) oferecem algumas pistas para essa pergunta quando analisam textos de alguns grupos de pesquisa vinculados ao estudo de currículo no país:

De forma geral, é interessante notar que o que tem sido denominado crise da Modernidade parece impactar todos os grupos. Fica claro que ninguém acredita em uma subjetividade unificada e autoconsciente; igualmente, há certo consenso de que a racionalidade falhou como esteio de 
um julgamento ético e político. Nesse sentido, uma subjetividade complexa, dividida, sobredeterminada, ganhou espaço em nossos estudos e nos fez caminhar, de muitas diferentes formas, para a ideia de que tais subjetividades são construídas discursivamente.

Como parte do embate contra o moderno, condenam-se as chamadas pedagogias críticas, caracterizadas pela sua aura salvacionista (Corazza, 1999), seu telos de conscientização, emancipação, esclarecimento e humanização, e pela "bondade pastoral" (Garcia, 2001) de um "professor profeta" (Gallo, 2003, p. 73).

Além disso, a perspectiva pós de pedagogia compromete-se em descolonizar o currículo (Silva, 1996), questionar as relaçōes de poder e, assim, dar vez às vozes ausentes na seleção da cultura escolar (Santomé, 1998), não diferenciar cultura erudita da cultura popular (Silva, 1996; Kellner, 1998), privilegiar o cotidiano escolar (Candau, 1999; Oliveira \& Alves, 1999) e da sala de aula (Gallo, 2003), conceber as identidades e a subjetividade como diluídas, contingentes e híbridas não apenas em termos culturais (Hall, 1998), mas também no sentido de um hibridismo tecno-humano, expresso no termo cyborgs (Haraway, 2000), entre tantas outras características.

As bases teóricas dessa perspectiva educacional são variadas: multiculturalismo crítico (McLaren, 2000; Canen et al., 2000), estudos feministas e de gênero (Silva, 2002; Hall, 1998), estudos culturais (Hall, 1998; Giroux, 1998), teoria queer (Silva, 2002; Louro, 2001), pós-estruturalismo (Silva, 1996, 2002; Veiga-Neto, 1994, 1999; Jones, 1998), pós-colonialismo, neopragmatismo (Ghiraldelli Jr., 1999, 2000a, 2000b, 2000c; Veiga-Neto, 1994, 1999; Popkewits, 1999), perspectivas do Programa Forte em Sociologia do Conhecimento (Wortmann \& Veiga-Neto, 2001).

Alguns autores explicitam as relações entre algumas dessas tendências teóricas. ${ }^{3}$ Por isso, mesmo quando algumas diferenças são apontadas entre elas, não é raro o uso do termo teorizações pós-críticas para aglutinar todas essas formas teóricas discursivas (Santos, 2000; Corazza, 1999; Silva, 2002; Paraíso, 2004).

Seguindo essa tendência, proponho pensar, a partir de Wood, a existência de uma agenda pós-moderna que, ao contrário do que se pode considerar, não remete para uma doutrina homogênea em termos de unidade conceitual. Nesse sentido, essa agenda não se reduz ao que 
classicamente ficou conhecido como pensamento pós-moderno: o pensamento de Lyotard e/ou a linhagem que articula as ideias lyotardianas do final dos anos de 1970 às máximas de Baudrillard, na década de 1990.

$\mathrm{O}$ termo em questão inclui a perspectiva desses autores, mas não se restringe a ela. Ele abarca outras diferentes perspectivas (multiculturalismo, neopragmatismo, pós-estruturalismo, construcionismo social etc.) que, apesar de suas diferenças (e aqui está a dificuldade), são perpassadas por motivaçôes e matrizes filosóficas convergentes e/ou aproximadas. O desafio, então, é explicar como essa agenda aglutina diferentes teorias e, mais especificamente, explicitar onde se encontra a convergência e/ou a aproximação dessas teorias que nela se abrigam. Para desenvolver esse ponto, trago para discussão a concepção epistemológica e ontológica dessas diversas orientaçōes teóricas que compõem a agenda pós. ${ }^{4}$

Em termos de concepção de ciência, essas diversas teorizaçôes trazem para a educação a contestação de que o conhecimento e a linguagem são representações da realidade. Veiga-Neto e Macedo (2007, p. 11-12) definem que

(...) as coisas e os fatos são aquilo que pensamos e dizemos que eles são (Wittgenstein, 1979). Na melhor das hipóteses, o que se pode dizer é "mesmo que exista uma realidade para além do nosso entendimento, ela só poderá ser pensada quando estiver sendo (minimamente) entendida e, nesse caso, já não estará mais para além do nosso entendimento (...)".

Em outro momento, ao explicar o ponto de vista foucaultiano, Veiga-Neto $(1994$, p. 8) ilustra este aspecto: "Essa me parece ser a posição de Foucault (...) no sentido de que só temos acesso ao mundo pelas representaçôes que fazemos (...)”. Em outras palavras, há um processo circular no qual a teoria descreveria uma descoberta que ela mesma criou (Silva, 2002). A estratégia aqui é submeter a razão a contextos culturais de justificação, como expressa McLaren (2000, p. 70): “(...) a racionalidade não é pan-histórica ou universal, mas está sempre situada em comunidades de discursos particulares".

Nesse sentido, a verdade perde seu elo com a objetividade e se torna uma interpretação: "A verdade é, sempre e já, interpretação. (...) Quem interpreta não descobre a 'verdade'; quem interpreta a produz. (...) Não há nada mais por detrás das perspectivas, para além delas. A verdade é isso: perspectivismo" (Silva, 2001, p. 4). 
A agenda pós-moderna na educação fornece elementos para apreender vários traços dos rumos das ciências humanas e da filosofia nos últimos anos e de como o pós-estruturalismo e o neopragmatismo se tangenciam. Porém, há um aspecto na compreensão de ciência da agenda pós que merece destaque, pois revela um fenômeno bastante disseminado: um ceticismo na produção do conhecimento que se traduz pela máxima de que nossas representações e esquemas conceituais constituem o real.

O ceticismo epistemológico reinante se nutre da postura antirrealista e relativista: a realidade é incognoscível, ou porque ela não existe, ou porque ela não passa de uma descrição ou convenção de uma comunidade. Aqui chegamos ao fio de Ariadne da agenda pós-moderna. Segundo Nanda (2002), o antirrealismo e o relativismo são os dois lados da falácia filosófica básica subjacente a todo pensamento pós-moderno: a tendência em afirmar que toda realidade é interna ao nosso sistema de representação e que, fora dela, tudo é considerado incognoscível. Essas posturas antirrealistas e relativistas se articulam intimamente, pois como não se pode, nesse contexto, avaliar nenhuma relação entre as crenças e a realidade, tanto a posição relativista como a cética tornam-se inevitáveis.

Nesse sentido, o foco da discussão refere-se a questóes ontológicas e gnosiológicas. Contudo, o que está em jogo são os seus desdobramentos éticos e políticos. Como demonstra Geras (1995), questôes do conhecimento, da verdade e da justiça se entrelaçam: não há justiça quando a verdade é completamente relativizada. ${ }^{5}$

Esse debate afeta profundamente a prática educativa, desde a sala de aula aos movimentos sociais. A educação é uma prática social que envolve decisões diversas, que vão desde a escolha de saberes considerados fundamentais até a perspectiva de sujeito que se pretende formar; ela se constitui, portanto, de inúmeras decisões éticas e políticas.

Pelo caminho da agenda pós-moderna, as tentativas de justificar racionalmente essas decisões ou se apresentam como uma ilusão, pois os fundamentos dessas decisões e preferências são lançados num abismo do qual todo esforço explicativo se esvai, ou ficam reféns da legitimação do sistema de crenças de uma comunidade, privilegiando, assim, a lida cotidiana e pragmática de um determinado grupo social. Se, por um lado, o niilismo desfigura a educação do seu caráter de prática que modifica 
os sujeitos envolvidos, por outro, o hipercontextualismo a transforma numa mera aculturação (Moraes, 2003).

O relativismo também possui desdobramentos para o fazer científico: a relativização ontológica desautoriza a ciência de sua função crítica. Nas palavras de Bhaskar (1975, p. 43), "Ser um cético sobre as coisas é ser um dogmático sobre o conhecimento". Para Duayer (2003a, p. 5),

(...) doutrinas que à primeira vista propugnam a relatividade, a indiferenciação, a equiparação de crenças, a total tolerância e o absurdo pluralismo, negam, pela lógica de sua própria construção, a possibilidade de crítica e, ipso facto, alimentam toda sorte de dogmatismo.

\section{A agenda pós-moderna e seu caráter criptopositivista}

Como visto, independente de admitir ou não a existência da efetividade em-si, a agenda pós-moderna a considera incognoscível. Nesse sentido, a realidade é definida por grupos, convenções, interpretações, acordos linguísticos, discursos, ou seja, em termos de açôes/operações humanas. A concreticidade da realidade torna-se, assim, produto da (inter)subjetividade. Iguala-se aqui o estatuto ontológico ao reconhecimento desse estatuto pelo ser humano. Para serem, os entes têm que ser para nós em uma experiência (linguística/discursiva) vivida.

Conhecer significa trazer as determinações ontológicas da realidade para o âmbito gnosiológico; transformar, pela mediação da linguagem, as coisas em-si em para-nós. Quando se aniquila o em-si pela ruptura entre ser e objetividade, só é aquilo que está em relação com o ser humano e é por ele conhecido. Essa tendência já presente no neopositivismo é, segundo Lukács (s/d), a forma mais pura da gnosiologia fundada sobre si própria. Por um longo tempo, a gnosiologia foi um complemento para a ontologia. Isso significava que sua finalidade era o conhecimento da efetividade e o critério de um enunciado correto era a concordância com o real. A quebra dessa relação é explicada por Lukács (s/d, p. 9): "Somente quando o em-si é considerado teoricamente inabordável, a gnosiologia torna-se autônoma, devendo-se classificar os enunciados como corretos ou falsos, independentemente de tal correspondência com o objeto (...)”. 
Quando o em-si é suprimido, o seu conhecimento racional também é desacreditado. Configura-se, assim, a crítica à objetividade e à universalidade do pensamento racional (Lukács, 1972).

Além disso, em termos gnosiológicos, o aniquilar do em-si conduz ao extremo arbítrio (Lukács, 2005). Lessa (1996) lembra que toda afirmação sobre o mundo é sempre uma afirmação sobre formas de ser. Ao se interditar qualquer referência ao em-si, o mundo se transforma em um constructo do investigador a partir de seus pressupostos. A dedução lógica do real que aí ocorre consiste em "(...) falsificar a representação da realidade, de modo que ela se conforme aos princípios metodológicos escolhidos arbitrariamente (...)" (Lessa, 1999, p. 13-14).

Ao contrário do neopositivismo que, segundo Lukács ( $\mathrm{s} / \mathrm{d}$, p. 11 ), sustenta a ilusão de que "a dadicidade dos objetos singulares não levanta questôes ontológicas", a agenda pós aprisiona a ontologia nas diversas singularidades e, nessa dissolução, transforma-a de uma teoria do ser em uma teoria do conhecer própria de cada singularidade. Portanto, essa agenda leva adiante aquilo que Lukács compreende como a unilateralidade da orientação exclusivamente gnosiológica e lógica em relação à efetividade. Com isso, cancela a distinção entre a própria efetividade e suas representaçôes (modos de seu conhecimento).

Um antropocentrismo oculto (Bhaskar, 1975, p. 39) habita essa perspectiva e leva à dissolução o próprio domínio do ontológico. Entretanto, qualquer tentativa de abolir a ontologia, seja por uma suposta neutralidade (como no neopositivismo), seja pela sua completa relativização (como na agenda pós), depara-se com o efeito de produzir uma ontologia implícita:

Como a ontologia não pode ser reduzida à epistemologia, esse erro simplesmente acoberta a geração de uma ontologia implícita, baseada na categoria da experiência, e de um realismo implícito, baseado nas características presumidas dos objetos em experiências, a saber, eventos atomísticos e suas relações, isto é, conjunções constantes. (Idem, ibid., p. 16).

Semelhante à análise lukacsiana, a reflexão de Bhaskar permite perceber que o relativismo ontológico, ao mesmo tempo em que leva à dissolução do campo ontológico, por subsumi-lo ao gnosiológico, gera uma ontologia implícita de natureza empiricista. O que é cognoscível é dado pela experiência sensível, pela descrição de padrôes de associação 
de eventos empíricos em sistemas fechados. O mundo é reduzido ao empírico, achatado a uma superfície rasa e confinado à sensibilidade (Bhaskar, 1975).

Se a ciência não se dirige para o conhecimento mais adequado possível da efetividade existente, sua atividade se limita, em última análise, a sustentar a práxis no sentido imediato, sua atividade torna-se uma manipulação dos fatos que interessam aos homens e mulheres, na prática. Assim, ao contrário da capa de antiontologia radical do neopositivismo, a agenda pós proclama a inevitabilidade da ontologia. No entanto, seu relativismo ontológico reafirma, na prática, o mesmo que Lukács reconheceu no neopositivismo: uma ontologia oculta, cuja base está na experiência e nas sensaçóes, e o critério privilegiado é a utilidade.

Ao tornarem a manipulação o eixo central do conhecimento científico, a tradição positivista, seu aparentado pragmatismo e a atual agenda pós-moderna assumem deliberadamente uma tendência que se vinculou a momentos menos desenvolvidos da ciência: o de permanecer sob o domínio prático-concreto de um complexo real (Lukács, s/d). Essa perspectiva agora é elevada à orientação geral da ciência.

A permanência de uma ontologia plasmada no empírico, quando o desenvolvimento científico já torna objetiva a possibilidade de uma ontologia correta, tem raízes nas necessidades sociais dominantes: “(...) a manipulação tornou-se, de modo especial na economia, um fator decisivo para a reprodução do capitalismo atual e, a partir deste ponto, irradiou-se para todos os campos da práxis social" (Lukács, op. cit., p. 31).

Diante das contribuiçóes de Lukács, somos tentados a declarar que vivemos uma ambiência ideológica similar à diagnosticada pelo autor: um ceticismo epistemológico, alimentado por supostas novidades filosóficas, mas que, no fundo, manifesta uma atmosfera criptopositivista. Enquanto a tradição positivista desterrou nominalmente a ontologia, as correntes atuais da agenda pós defendem a impossibilidade de escapar dela. Entretanto, ao relativizá-la, refutam a possibilidade de dizer algo sobre o mundo e decretam o conhecimento como constructo e a verdade como consenso. Dessa forma, as declaraçôes sobre o ser tornam-se declaraçôes sobre o nosso conhecimento sobre o ser. Substitui-se a ontologia pela gnosiologia e, nesse sentido, vive-se, segundo Duayer (2003b), uma nova forma de exílio da ontologia, no 
qual a ontologia é afirmada, mas para ser negada. O resultado desse processo é, como assinala Lukács (s/d), o fortalecimento de uma ontologia velada, estreitamente vinculada a uma prática imediata, conveniente aos interesses manipulatórios do capital.

Em termos sociais, as aproximaçóes entre o neopositivismo e a agenda pós precisam ser um pouco matizadas. Lukács (2005) lembra que, em sua descrição da manipulação geral da vida, Carnap demonstra seu acordo (revestido de uma suposta neutralidade) com essa situação. $\mathrm{Na}$ agenda pós-moderna, há uma espécie de contestação que avista um leque amplo de variações: desde a renúncia de ideais de emancipação e autonomia (cf. Baudrillard, 1996; Lyotard, 2000), a defesa de utopia liberal como pertencente à esquerda reformista (cf. Rorty, 2001), até uma resistência a partir de minirracionalidades (cf. Santos, 1999).

A rejeição do questionamento da realidade resulta, assim, por um lado, de uma satisfação com a manipulação geral da vida; por outro, de uma repulsa (Lukács, 2005). Contudo, neste suposto distanciamento entre o neopositivismo e a agenda pós, reside mais uma de suas aproximações. De acordo com Ahmad (2001), uma das peculiaridades do pós-moderno está não apenas no alívio, mas na euforia diante do colapso (considerado definitivo) dos três principais projetos de emancipação universal do século xx: o nacionalismo anti-imperialista, a democracia social de esquerda e o comunismo. Nesse sentido, a aparente contestação pós-moderna consiste em uma “(...) repulsa de quem está completamente persuadido, intimamente, da inutilidade do esforço para liberar-se da alienação, e por isso procura e encontra uma autoconfirmação interior, precisamente na inutilidade da própria rejeição" (Lukács, 2005, p. 20). Assim, nenhuma dessas perspectivas “(...) é capaz ou menos deseja pensar um possível futuro para a humanidade que possa ser basicamente diferente do atual triunfo neoliberal e a consequente universalização do fetichismo da mercadoria" (Ahmad, 2001, p. 3). A associação mais substantiva entre o neopositivismo e a agenda pós-moderna é o compromisso comum com a democracia capitalista.

\section{Considerações finais}

Buscamos, neste artigo, evidenciar o lugar que o pós-estruturalismo e o neopragmatismo ocupam na produção do conhecimento 
referente aos estudos do currículo, assim como os desdobramentos éticos, políticos e filosóficos dessas orientaçôes teóricas para o campo educacional em geral.

Como visto, a despeito de suas diferenças, o diálogo entre o pósestruturalismo e o neopragmatismo, no que se refere às questôes curriculares, necessita ser compreendido tendo em vista a inserção dessas duas perspectivas filosóficas em uma ampla agenda, que pode ser denominada de pós-moderna. Em suas diferentes versōes, essa agenda possui um eixo comum derivado de sua negação da universalidade da razão, da verdade e da ciência: a impossibilidade de o conhecimento dizer algo sobre a realidade objetiva, por ser ele um produto do sistema de crenças de uma comunidade. Toda a discussão da verdade desloca-se para o âmbito da linguagem, mais precisamente para o exercício semântico e alegórico (e, por não dizer, sofista) que afaste qualquer traço de conceituação.

Com essa posição, a agenda pós delineia sua discordância da neutralidade advogada pelos positivistas: o conhecimento não é neutro, mas produto dos interesses, valores, crenças de uma comunidade. A despeito de sua luta contra o positivismo, esta agenda é portadora de um caráter criptopositivista. O neopositivismo suspende o ontológico e exclui da ciência questôes relativas à concepção de mundo. Qualquer referência a uma realidade efetiva soa metafísica para essa perspectiva e, como tal, insignificante em termos científicos. A agenda pós-moderna tem um ponto de partida oposto ao neopositivismo: ela argumenta que é impossível desviar-se da ontologia e que o estatuto ontológico da realidade é dado pelos diversos modos de se abordar linguisticamente essa realidade. Ao efetivar esse relativismo ontológico, tal agenda sucumbe, por outra via, à mesma interdição de referência ao real que o neopositivismo.

Com isso, a agenda pós passa a compartilhar também com o (neo)positivismo aquilo que Loureiro (2007) identificou como o núcleo comum dessa tradição: a corrosão da teoria pela prática, entendida em seu caráter imediato, e o esvaziamento da relação entre verdade e mundo objetivo, por meio do privilégio da eficácia. Trata-se, portanto, de uma relação entre "antípodas solidários", semelhante àquela que Lukács (1979) identificou entre o neopositivismo e o existencialismo.

Por essa razão, Duarte $(2000$, p. 79$)$ destaca a significativa importância da chamada "troca de experiências em encontros da área 
educacional: em nome da valorização da experiência profissional de cada professor, o que acaba por existir é a legitimação do imediatismo, do pragmatismo e da superficialidade que caracterizam o cotidiano alienado". Por sua vez, Moraes (2004) alerta que a celebração do "fim da teoria" caminha pari passu com a promessa de uma utopia educacional, alimentada por um indigesto pragmatismo que ganha forma nos critérios que têm norteado a elaboração das prioridades educativas nas políticas de formação, na elaboração de currículos, na organização da escola: “(...) em suma, em um projeto político que investe numa concepção empobrecida de pesquisa e na formação de um docente pouco adepto ao exercício do pensamento" (Moraes, op. cit., p. 352).

Diante disso, não é difícil perceber que a agenda pós revela-se como um componente ideológico do capitalismo contemporâneo. Por mais que alguns intelectuais dessa agenda mostrem desconforto com facetas do viver sob o capitalismo, suas propostas de transgressões pontuais e contingentes, apesar de se mostrarem, muitas vezes, interessantes, quando muito, arranham, de leve, a estrutura social.

Em um contexto no qual o capitalismo revela a sua face mais perversa e sua impossibilidade de garantir uma vida digna a todos, qualquer teoria que assuma a tarefa de desvendar facetas do mundo objetivo é combatida e desacreditada. Estar a contrapelo desse processo implica, no âmbito da produção do conhecimento, corroborar o apelo de Lukács (s/d, p. 15): “(...) a efetiva exigência que hoje se põe é retornar à efetividade existente em si”. Porém, realizar tal dinâmica requer, acima de tudo, recuperar o papel do filósofo de "(...) velar pela existência e pelo desenvolvimento da razão" (Lukács, 1972, p. 74), contra quaisquer tentativas de seu aniquilamento.

Recebido em maio de 2009 e aprovado em dezembro de 2009.

\section{Notas}

1. Aliás, este é o programa presente na proposta de elaborar a história sofistica da filosofia, de Cassin (2005).

2. Apesar da publicação no Brasil ocorrer em 1999, o livro no qual se encontra o artigo de Wood foi originalmente lançado em inglês em 1997. Porém, especificamente, o texto de Wood "Em defesa da história: o marxismo e a agenda pós-moderna" já possuía uma versão em português devido a sua publicação em 1996 na Crítica Marxista (CEMarX, Campinas, n. 3, p. 118-129). 
Agenda pós-moderna e neopositivismo: antípodas solidários

3. Sobre a convergência das análises pós-colonial, pós-moderna e pós-estruturalista, consultar Silva (2002). Quanto à confluência entre os estudos culturais com as perspectivas do Programa Forte em Sociologia do Conhecimento (como as da Escola de Edimburgo, abordagens construcionista-relativistas, estudos etnográficos de laboratório, análises discursivas à ciência), o pensamento pós-estruturalista e as filosofias pós-modernas, ver Wortmann e Veiga-Neto (2001).

4. Reconheço que tomar o pós-moderno como uma agenda ampla, que inclui diversas correntes intelectuais contemporâneas, é um procedimento passivo de críticas, em especial por aqueles que buscam evidenciar diferenças entre correntes. Peters (2000) distingue, por exemplo, pós-estruturalismo e pós-modernismo em termos de contexto de surgimento e formulaçôes teóricas. Ele afirma que o pós-estruturalismo é uma resposta filosófica que começa na França, no início dos anos de 1960, marcada pelo questionamento radical do sujeito humanista, reação ao hegelianismo, crítica da razão e dos valores iluministas, entre outros. Já o pós-modernismo é, segundo o autor, uma resposta estética que se desenvolve a partir do contexto do alto modernismo. Porém, como mencionado, já existem, no campo acadêmico, tentativas de aglutinar essas formas teóricas e/ou sugerir aproximações entre elas, sob o rótulo de teorizações pós-críticas. Com o termo "agenda pós-moderna", acompanho esse movimento e sugiro um eixo comum compartilhado por essas diferentes perspectivas. Não se trata de igualá-las em suas proposiçôes, mas de indicar que, na diversidade de seus argumentos, podem ser identificadas algumas aproximaçóes e semelhanças que, a meu ver, manifestam a atmosfera político-intelectual vigente.

5. Loureiro e Della Fonte (2007) chamam a atenção para o fato de que, a despeito das posições políticas de autores considerados pós-modernos, há a cumplicidade a contragosto entre suas teses céticas e relativistas e a difusão do revisionismo histórico do Holocausto. Nesse sentido, é exemplar a argumentação dos advogados de defesa do empresário Siegfried Ellwanger (proprietário da editora Revisão no Rio Grande do Sul), condenado pela justiça brasileira por racismo em 2003, devido à publicação de livros e revistas de cunho antissemita. A fim de pleitear um habeas corpus no Supremo Tribunal Federal, entre os vários argumentos aventados, os advogados do empresário alegaram que a obra de revisão histórica não passava de uma mera interpretação de fatos passados (como outras), sob um viés ideológico de denúncia do sionismo.

\section{Referências}

AHMAD, A. A teoria pós-colonial e a "condição-pós"; texto base para conferência ministrada na York University, Torono, em 27 de novembro de 1996. Trad. de Maria Célia M. Moraes. Florianópolis, UFSC, 2001.

BAUDRILLARD, J. O crime perfeito. Lisboa: Relógio D’Água, 1996.

BHASKAR, R. A realist theory of science. Leeds: Books, 1975.

CANDAU, V.M. Cotidiano escolar e cultura(s): encontros e desencontros. In: REUNIĀO ANUAL DA ASSOCIAÇÃO NACIONAL 
DE PÓS-GRADUAÇÃO E PESQUISA EM EDUCAÇÃO, 22., 1999, Caxambu. Anais... Caxambu: anped, 1999.

CANEN, A. et al. Pesquisando multiculturalismo e educação: o que dizem as dissertações e teses. In: REUNIÃO ANUAL DA ASSOCIAÇÃO NACIONAL DE PÓS-GRADUAÇÃO E PESQUISA EM EDUCAÇÃO, 23., 2000, Caxambu. Anais... Caxambu: ANPEd, 2000.

CASSIN, B. O efeito sofístico. São Paulo: Editora 34, 2005.

CORAZZA, S.M. Currículo como modo de subjetivação do infantil. In: REUNIÃO ANUAL DA ASSOCIAÇÃO NACIONAL DE PÓSGRADUAÇÃO E PESQUISA EM EDUCAÇÃO, 22., 1999, Caxambu. Anais... Caxambu: ANPEd, 1999.

CORAZZA, S.M. Pesquisar o currículo como acontecimento: em V exemplos. In: REUNIÂO ANUAL DA ASSOCIAÇÃO NACIONAL DE PÓS-GRADUAÇÃO E PESQUISA EM EDUCAÇÃO, 27., 2004, Caxambu. Anais... Caxambu: Anped, 2004. Disponível em: <http://www.anped.org.br/reunioes/27/gt12/t1211.pdf, p. 2>. Acesso em: 30 abr. 2006.

DELACAMPAGNE, C. História da filosofia no século XX. Rio de Janeiro: Zahar, 1997.

DUARTE, N. Vigotski e o "aprender a aprender": crítica às apropriações neoliberais e pós-modernas da teoria vigotskiana. Campinas: Autores Associados, 2000.

DUAYER, M. Economia depois do relativismo: crítica ontológica ou ceticismo instrumental? Niterói: UfF, 2003a. 14p. (Mimeo.).

DUAYER, M. Ontologia na ciência econômica: realismo ou ceticismo instrumental? Niterói: UFF, 2003b. (Mimeo.).

GALlO, S. Deleuze e a educação. Belo Horizonte: Autêntica, 2003.

GARCIA, M.M.A. Currículo e formação docente: a ética do mestre pastoral crítico. In: REUNIÃO ANỦAL DA ASSOCIAÇÃO NACIONAL DE PÓS-GRADUAÇÃO E PESQUISA EM EDUCAÇÃO, 24., 2001, Caxambu. Anais... Caxambu: Anped, 2001. GT 12 - Currículo. 
Agenda pós-moderna e neopositivismo: antípodas solidários

GERAS, N. Language truth and justice. New Left Review, London, n. 209, p. 110-135, jan./fev. 1995.

GHIRALDELLI JUNIOR. P. O que é filosofia da educação: uma discussão metafísica. In: GHiraldelli Junior, P. (Org.). O que é filosofia da educação? Rio de janeiro: DP\&A, 1999. p. 7-87.

GHIRALDELLI JUNIOR, P. A questão da filosofia da educação e a filosofia da educação "em questão" - verdade e discurso pedagógico na abertura do século XXI: ou Quem é quem na "Escada de Ramsey" na filosofia da educação. In: GHiraldelli Junior, P. (Org.). Estilos em filosofia da educação. Rio de Janeiro: DP\&A, 2000a. p. 9-23.

GHIRALDELLI JUNIOR, P. O que há de real e de irreal com o realismo?: Searle versus Rorty. In: GHiraldelli Junior, P. (Org.). Estilos em filosofia da educação. Rio de Janeiro: DP\&A, 2000b. p. 73-86.

GHIRALDELLI JUNIOR, P. Filosofia da educação. Rio de Janeiro: DP\&A, 2000c.

GIROUX, H.A. Praticando estudos culturais nas faculdades de educação. In: Silva, T.T. (Org.). Alienígenas na sala de aula: uma introdução aos estudos culturais em educação. 2. ed. Petrópolis: Vozes, 1998. p. 85-103.

HALL, S. A identidade cultural na pós-modernidade. 2. ed. Rio de Janeiro: DP\&A, 1998.

HARAWAY, D.J. Manifesto ciborgue: ciência, tecnologia e feminismo-socialista no final do século XX. In: SiLva, T.T. (Org.). Antropologia do ciborgue: as vertigens do pós-humano. Belo Horizonte: Autêntica, 2000. p. 37-129.

JONES, D.M. Foucault e a possibilidade de uma pedagogia sem redenção. In: Silva, T.T. (Org.). O sujeito da educação: estudos foucaultianos. 3. ed. Petrópolis: Vozes, 1999. p. 111-126.

KELLNER, D. Lendo imagens criticamente: em direção a uma pedagogia pós-moderna. In: Silva, T.T. (Org.). Alienígenas na sala de aula: uma introdução aos estudos culturais em educação. Petrópolis: Vozes, 1998. p. 104-131. 
LESSA, S. Para uma ontologia do ser social. In: Antunes, R.; RêGo, W.L. (Org.). Lukács: um Galileu no século Xx. 2. ed. São Paulo: Boitempo, 1996. p. 62-73.

LESSA, S. Notas sobre a historicidade da essência em Lukács. Novos Rumos, São Paulo, v. 30, p. 22-30, 1999. Disponível em: <www. geocities.com/srglessa>. Acesso em: 2 ago. 2006.

LOUREIRO, R. Aversão à teoria e indigência da prática: crítica a partir da filosofia de Adorno. Educação \& Sociedade, Campinas, v. 28, n. 99, p. 522-541, 2007.

LOUREIRO, R.; DELLA FONTE, S.S. O revisionismo histórico e o pós-moderno: indicações de um encontro inesperado. 2007. [não publicado].

LOURO, G.L. Teoria queer: uma política pós-identitária para a educação. Revista de Estudos Feministas, Florianópolis, v. 9, n. 2, p. 541-553, 2001. Disponível em: <http://www.scielo.br/scielo.php?pid=S0104026X2001000200012\&script=sci_arttext\#b23>. Acesso em: 24 jun. 2006.

LUKÁCS, G. El asalto a la razón: la trayectoria del irracionalismo desde Schelling hasta Hitler. 3. ed. Barcelona: Grijalbo, 1972.

LUKÁCS, G. Ontologia do ser social: os princípios ontológicos fundamentais de Marx. São Paulo: Ciências Humanas, 1979.

LUKÁCS, G. Existencialismo. Trad. de Maria Izabel Porto de Souza. [s.1.: s.n.], 2005. 23p.

LUKÁCS, G. Neopositivismo. Trad. preparada por Mário Duayer. (correspondente à primeira seção do capítulo 1: Neopositivismo e existencialismo, da obra LUKÁCS, G. Zur Ontologie des gesellschaftlichen Seins). Versão preliminar. Niterói: UFF [s.d.]. 19p.

LYOTARD, J.F. A condição pós-moderna. 6. ed. Rio de Janeiro: José Olympio, 2000.

MCLAREN, P. Multiculturalismo crítico. 3. ed. São Paulo: Cortez; Instituto Paulo Freire, 2000. 
Agenda pós-moderna e neopositivismo: antípodas solidários

MORAES, M.C.M. Os “pós-ismos” e outras querelas ideológicas. Perspectiva, Florianópolis, v. 14, n. 25, p. 45-60, jan./jun.1996.

MORAES, M.C.M. Recuo da teoria. In: Moraes, M.C.M. (Org.). Iluminismo às avessas. Rio de Janeiro: DP\&A, 2003. p. 151-167.

MORAES, M.C.M. O renovado conservadorismo da agenda pós-moderna. Cadernos de Pesquisa, São Paulo, v. 34, n. 122, p. 337-357, maio/ago. 2004.

NANDA, M. Restaurando a realidade: repensando as teorias sociais construtivistas. Trad. livre de Maria Célia M. Moraes e Patrícia Torriglia. Florianópolis: PPGE-UfSC, 2002. 31p.

OLIVEIRA, I.B.; ALVES, N. Cotidiano, redes de conhecimentos e valores. In: REUNIÃO ANUAL DA ASSOCIAÇÃO NACIONAL DE PÓS-GRADUAÇÃO E PESQUISA EM EDUCAÇÃO, 22., 1999, Caxambu. Anais... Caxambu: anped, 1999.

PARAÍSO, M.A. Pesquisas pós-críticas em educação no Brasil: esboço de um mapa. Cadernos de pesquisa, São Paulo, v. 34, n. 122, p. 238303, maio/ago. 2004.

PETERS, M. Pós-estruturalismo e filosofia da diferença: uma introdução. Belo Horizonte: Autêntica, 2000.

PLATÃO. Sofista. São Paulo: Abril Cultural, 1987. p. 127-195. (Coleção Os pensadores).

POPKEWITZ, T.S. História do currículo, regulação social e poder. In: Silva, T.T. (Org.). O sujeito da educação: estudos foucaultianos. 3. ed. Petrópolis: Vozes, 1999. p. 173-210.

RORTY, R. A filosofia e o espelho da natureza. Rio de Janeiro: Relume-Dumará, 1994.

RORTY, R. Ensaios sobre Heidegger e outros: escritos filosóficos 2. Rio de Janeiro: Relume-Dumará, 1999.

RORTY, R. Contra os chefes, contra as oligarquias. São Paulo: DP\&A, 2001.

SANTOMÉ, J.T. As culturas negadas e silenciadas no currículo. In: Silva, T.T. (Org.). Alienígenas na sala de aula: uma introdução aos 
estudos culturais em educação. 2. ed. Petrópolis: Vozes, 1998. p. 159-189.

SANTOS, B.S. Pela mão de Alice: o social e o político na pós-modernidade. 6. ed. São Paulo: Cortez, 1999.

SANTOS, S.L. A logogização do infantil: uma prática escolar. In: REUNIÃO ANUAL DA ASSOCIAÇÃO NACIONAL DE PÓS-GRADUAÇÃO E PESQUISA EM EDUCAÇÃO, 23., 2000, Caxambu. Anais... Caxambu: ANPEd, 2000.

SILVA, T.T. Identidades terminais: as transformações na política da pedagogia e na pedagogia da política. Petrópolis: Vozes, 1996.

SILVA, T.T. Dr. Nietzsche, curriculista: com uma pequena ajuda do professor Deleuze. In: REUNIÃO ANUAL DA ASSOCIAÇÁO NACIONAL DE PÓS-GRADUAÇÃO E PESQUISA EM EDUCAÇÃO, 24., 2001, Caxambu. Anais... Caxambu: ANPEd, 2001.

SILVA, T.T. Documentos de identidade: uma introdução às teorias do currículo. 2. ed. Belo Horizonte: Autêntica, 2002.

VEIGA-NETO, A. A sociologia da educação e Michel Foucault. In: REUNIÃO ANUAL DA ASSOCIAÇÃO NACIONAL DE PÓS-GRADUAÇÃO E PESQUISA EM EDUCAÇÃO, 17., 1994, Caxambu. Anais... Caxambu: ANPEd, 1994.

VEIGA-NETO, A. Foucault e educação: outros estudos foucaultianos. In: Silva, T.T. (Org.). O sujeito da educação: estudos foucaultianos. 3. ed. Petrópolis: Vozes, 1999. p. 225-246.

VEIGA-NETO, A.; MACEDO, E. Estudos curriculares: como lidamos com os conceitos de moderno e pós-moderno? In: REUNIÃO ANUAL DA ASSOCIAÇÃO NACIONAL DE PÓS-GRADUAÇÃO E PESQUISA EM EDUCAÇÃO, 30., 2007, Caxambu. Anais... Caxambu, ANPED, 2007. Disponível: em: <http://www.anped.org.br/reunioes/ $30 \mathrm{ra} /$ trabalhos_encomendados/trabalho $\% 20$ encomendado $\% 20 \mathrm{gt} 12 \%$ 20-\%20alfredo\%20veiga-neto\%20-\%20int.pdf>. Acesso em: 3 mar. 2008 .

WOOD, E.M. O que é a agenda "pós-moderna"? In: Wood, E.M.; Foster, J.B. (Org.). Em defesa da história: marxismo e pós-modernismo. Rio de Janeiro: Zahar, 1999. p. 7-22. 
Agenda pós-moderna e neopositivismo: antípodas solidários

WORTMANN, M.L.C.; VEIGA-NETO, A. Estudos culturais da ciência e educação. Belo Horizonte: Autêntica, 2001. 